\title{
Innovative academic startups 2015
}

\author{
Brady Huggett
}

$\bigwedge_{\text {amount of venture capital raised (Table 1) continues to be domi- }}$ in 2015 (Fig. 1). Elsewhere in the world, the UK, China, Canada, Switzerland and France were the next most successful locations in terms nated by US ventures ( 7 of 10). Greater access to capital explains why the United States recorded 67 ventures of all types securing A rounds of capitalization, with 10, 6, 5, 3 and 3 companies, respectively; the UK tops the list of average amount raised per round (Table 2).

Table 1 Top ten series A rounds in 2015 for innovative academic startups (as of December 15)

\begin{tabular}{|c|c|c|c|c|}
\hline Company & $\begin{array}{l}\text { Amount raised (millions); } \\
\text { date; investors }\end{array}$ & Scientific founders & Other founders & Technology \\
\hline $\begin{array}{l}\text { Gritstone Oncology } \\
\text { (Emeryville, CA, USA) }\end{array}$ & $\begin{array}{l}\text { \$102; Oct. 20; Versant } \\
\text { Ventures, The Column } \\
\text { Group, Clarus Ventures, } \\
\text { Frazier Healthcare, } \\
\text { Redmile Group, Casdin } \\
\text { Capital, Transformational } \\
\text { Healthcare Opportunity }\end{array}$ & $\begin{array}{l}\text { Tim Chan, Memorial Sloan Kettering Cancer } \\
\text { Center; Mark Cobbold, Massachusetts General } \\
\text { Hospital Cancer Center and Harvard Medical } \\
\text { School; Graham Lord, King's College London; } \\
\text { Naiyer Rizvi, Columbia University Medical Center; } \\
\text { Jean-Charles Soria, South-Paris University }\end{array}$ & $\begin{array}{l}\text { Andrew Allen, } \\
\text { former CEO, Clovis } \\
\text { Oncology }\end{array}$ & $\begin{array}{l}\text { Identifying patient-derived, tumor-specific neoantigens } \\
\text { for the development of individualized synthetic cancer } \\
\text { vaccines }\end{array}$ \\
\hline $\begin{array}{l}\text { Neon Therapeutics } \\
\text { (Cambridge, MA, USA) }\end{array}$ & $\begin{array}{l}\$ 55 ; \text { Oct. } 1 ; \text { Third } \\
\text { Rock Ventures, Clal } \\
\text { Biotechnology Industries, } \\
\text { Access Industries }\end{array}$ & $\begin{array}{l}\text { James Allison, The University of Texas MD } \\
\text { Anderson Cancer Center; Nir Hacohen, } \\
\text { Broad Institute; Eric Lander, Broad Institute; } \\
\text { Robert Schreiber, Washington University; Ton } \\
\text { Schumacher, The Netherlands Cancer Institute; } \\
\text { Catherine Wu, Dana-Farber Cancer Institute }\end{array}$ & $\begin{array}{l}\text { Ed Fritsch, formerly } \\
\text { at Dana-Farber } \\
\text { Cancer Institute } \\
\text { and the Broad } \\
\text { Institute of MIT and } \\
\text { Harvard }\end{array}$ & $\begin{array}{l}\text { Identifying patient-derived, tumor-specific neoantigens } \\
\text { for the development of individualized and off-the-shelf } \\
\text { cancer vaccines }\end{array}$ \\
\hline $\begin{array}{l}\text { Decibel Therapeutics } \\
\text { (Cambridge, MA, USA) }\end{array}$ & $\begin{array}{l}\text { \$52; Oct. 15; Third Rock } \\
\text { Ventures, SR One }\end{array}$ & $\begin{array}{l}\text { M. Charles Liberman, Harvard Medical School; } \\
\text { Gabriel Corfas, University of Michigan; Ulrich } \\
\text { Müller, Scripps Research Institute; Albert Edge, } \\
\text { Harvard Medical School }\end{array}$ & Not applicable & $\begin{array}{l}\text { Novel therapies for hearing loss to modulate such } \\
\text { targets as atonal homolog } 1 \text { (Neuron } 77,58-69 \text {, } \\
\text { 2013), repulsive guidance molecule A or its receptor, } \\
\text { neogenin }\end{array}$ \\
\hline $\begin{array}{l}\text { Revolution Medicines } \\
\text { (Redwood City, CA) }\end{array}$ & $\begin{array}{l}\$ 45 ; \text { Feb. 4; Third Rock } \\
\text { Ventures }\end{array}$ & $\begin{array}{l}\text { Martin Burke, University of Illinois at Urbana- } \\
\text { Champaign }\end{array}$ & $\begin{array}{l}\text { Mark Goldsmith, } \\
\text { Third Rock; David } \\
\text { Pompliano, Third } \\
\text { Rock }\end{array}$ & $\begin{array}{l}\text { Automated chemical synthesis of } N \text {-methyliminodiacetic } \\
\text { acid-boronate containing intermediates (Science } 347 \text {, } \\
1121-1226,2015) \text { to generate amphotericin analogs } \\
\text { with antifungal activity ( } N \text {. Chem. Biol. 11, 481-487, } \\
\text { 2015) }\end{array}$ \\
\hline $\begin{array}{l}\text { Semma Therapeutics } \\
\text { (Cambridge, MA, USA) }\end{array}$ & $\begin{array}{l}\$ 44 ; \text { March } 24 ; \\
\text { MPM Capital, Fidelity } \\
\text { Biosciences, Arch Venture } \\
\text { Partners, Medtronic }\end{array}$ & $\begin{array}{l}\text { Doug Melton, Harvard; Felicia Pagliuca, previously } \\
\text { a post-doctoral fellow in Melton's laboratory at } \\
\text { Harvard }\end{array}$ & $\begin{array}{l}\text { Robert Millman, } \\
\text { MPM Capital; } \\
\text { Jeff Imbaro, previ- } \\
\text { ously at Pursuit } \\
\text { Solutions }\end{array}$ & $\begin{array}{l}\text { Cell transplantation treatments for type I diabetes } \\
\text { based on human pancreatic beta-like cells derived } \\
\text { from ESC or iPSC (Cell 159, 428-439, 2014) }\end{array}$ \\
\hline $\begin{array}{l}\text { Freeline Therapeutics } \\
\text { (London) }\end{array}$ & $\begin{array}{l}\text { \$37.7; Dec. 10; Syncona } \\
\text { Partners }\end{array}$ & Amit Nathwani, University College London & $\begin{array}{l}\text { Christian } \\
\text { Groendahl, } \\
\text { Syncona }\end{array}$ & $\begin{array}{l}\text { Pseudotyped, self-complementary adenovirus- } \\
\text { associated virus subtype } 8 \text { vector expressing codon- } \\
\text { optimized human factor IX for patients with hemophilia } \\
\text { B (N. Engl. J Med. } \mathbf{3 6 5}, 2357-2365,2011)\end{array}$ \\
\hline Metacrine (San Diego) & $\begin{array}{l}\$ 36 \text {; Aug. 5; Arch Venture } \\
\text { Partners, EcoR1 Capital, } \\
\text { Polaris Partners, venBio }\end{array}$ & $\begin{array}{l}\text { Ronald Evans, Salk Institute; Michael Downes, } \\
\text { Salk Institute }\end{array}$ & $\begin{array}{l}\text { Rich Heyman, } \\
\text { previously CEO of } \\
\text { Seragon }\end{array}$ & $\begin{array}{l}\text { Protein sensitizers for insulin in type } 2 \text { diabetes and } \\
\text { modulators of farnesoid-activated receptors for non- } \\
\text { alcoholic steatohepatitis and other metabolic diseases }\end{array}$ \\
\hline $\begin{array}{l}\text { TherAchon (Biot, } \\
\text { France) }\end{array}$ & $\begin{array}{l}\text { \$35; Sept. 30; OrbiMed } \\
\text { Advisors, New Enterprise } \\
\text { Associates, Inserm } \\
\text { Transfert, Versant Ventures }\end{array}$ & $\begin{array}{l}\text { Elvire Gouze, Inserm, University of Nice Sophia } \\
\text { Antipolis }\end{array}$ & NA & $\begin{array}{l}\text { Soluble human fibroblast growth factor (FGF) receptor } \\
3 \text { decoy prevents binding of FGF to mutant FGFR3 in } \\
\text { achondroplasia (Sci. Transl. Med. } 5,203 \text { ra124, 2013) }\end{array}$ \\
\hline $\begin{array}{l}\text { Kesios Therapeutics } \\
\text { (London) }\end{array}$ & $\begin{array}{l}\text { \$28.8; Dec. 2; Imperial } \\
\text { Innovations Group, SV Life } \\
\text { Sciences, Abingworth }\end{array}$ & $\begin{array}{l}\text { Guido Franzoso, Imperial College London; Menotti } \\
\text { Ruvo, Istituto di Biostrutture e Bioimmagini of } \\
\text { CNR; Laura Tornatore, Imperial College London }\end{array}$ & NA & $\begin{array}{l}\text { Preclinical compounds targeting GADD45/MKK7 } \\
\text { complex downstream of NFkappaB (Cancer Cell 26, } \\
495-508,2014 \text { ) for multiple myeloma }\end{array}$ \\
\hline $\begin{array}{l}\text { Neurona Therapeutics } \\
\text { (S. San Francisco, CA, } \\
\text { USA) }\end{array}$ & $\begin{array}{l}\text { \$23.5; Dec. 1; The } \\
\text { Column Group, Topspin } \\
\text { Partners, private investors }\end{array}$ & $\begin{array}{l}\text { Cory Nicholas, University of California, San } \\
\text { Francisco (UCSF); Arnold Kriegstein, UCSF; Arturo } \\
\text { Álvarez-Buylla, UCSF; John Rubenstein, UCSF }\end{array}$ & NA & $\begin{array}{l}\text { Transplantation of human ESC- and iPSC-derived } \\
\gamma \text {-aminobutyric acid-secreting (GABAergic) interneu- } \\
\text { rons for epilepsy, neuropathic pain, spasticity and cer- } \\
\text { tain cognitive impairments and psychoses cells. }\end{array}$ \\
\hline
\end{tabular}

Source: $\mathrm{BCIQ}$ : BioCentury Online Intelligence; company materials.

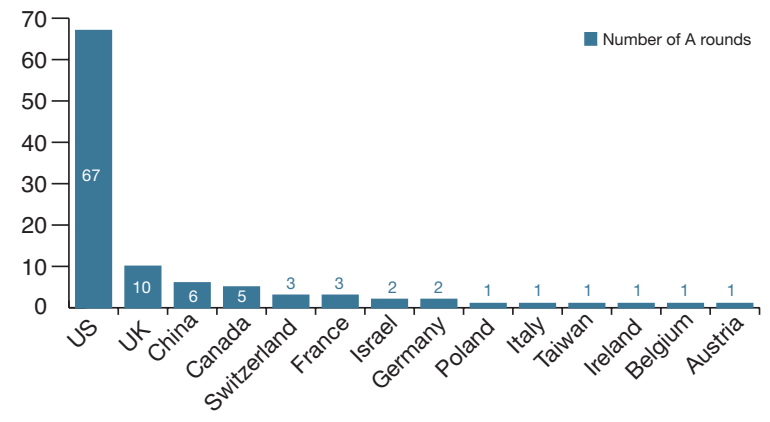

Figure 1 Number of startups by country, 2015. A-2 rounds of undisclosed amounts left out. Source: BCIQ: BioCentury Online Intelligence.

Brady Huggett is business editor at Nature Biotechnology.
Table 2 Total and average series A rounds by country, 2015

\begin{tabular}{lcc}
$\begin{array}{l}\text { Country (number of } \\
\text { rounds) }\end{array}$ & $\begin{array}{l}\text { Total amount raised } \\
\text { (\$ millions) }\end{array}$ & $\begin{array}{l}\text { Average raised per round } \\
\text { (\$ millions) }\end{array}$ \\
\hline UK (10) & 516.2 & $51.6^{\mathrm{a}}$ \\
\hline Belgium (1) & 31.2 & 31.2 \\
\hline US (67) & $1,482.2$ & 22.1 \\
\hline France (3) & 51.6 & 17.2 \\
\hline China (6) & 89 & 14.8 \\
\hline Canada (5) & 72.6 & 14.5 \\
\hline Switzerland (3) & 43 & 14.3 \\
\hline Germany (2) & 27.1 & 13.5 \\
\hline Italy (1) & 11.2 & 11.2 \\
\hline Taiwan (1) & 8 & 8
\end{tabular}

A-2 rounds, and rounds of undisclosed amounts left out. Source: BCIQ: BioCentury Online Intelligence. aWithout outlier Immunocor, \$21.8. 